\title{
Anaesthetic management of a three-month-old baby for cervical limited dorsal myeloschisis repair using propofol and alfentanil infusions guided by pharmacokinetic simulation software: A case report
}

\author{
E Coetzee, ${ }^{1}$ R Gray, ${ }^{1}$ C Hollman, ${ }^{1}$ JMN Enslin, ${ }^{2}$ JF Coetzee ${ }^{3}$ \\ ${ }^{1}$ Department of Anaesthesia and Perioperative Medicine, Red Cross War Memorial Children's Hospital, University of Cape Town, South Africa \\ ${ }^{2}$ Division of Neurosurgery, Red Cross War Memorial Children's Hospital, University of Cape Town, South Africa \\ ${ }^{3}$ Department of Anaesthesiology and Critical Care, Stellenbosch University, South Africa \\ Corresponding author, email: ettiennec@gmail.com
}

We present an uncommon case of limited dorsal myeloschisis in a 3-month-old infant requiring repair guided by intraoperative neuromonitoring (IONM) and therefore avoidance of volatile anaesthetic agents. The case presented challenges in positioning, airway management, a lack of age appropriate pharmacokinetic models in target-controlled infusion (TCI) syringe pumps and unavailability of remifentanil, considered to be an essential drug in this setting. We overcame these challenges using manually controlled infusions of propofol and alfentanil guided by pharmacokinetic simulation software (Stelsim).

Keywords: cervical limited dorsal myeloschisis, intraoperative neuromonitoring (IONM), total intravenous anaesthesia (TIVA), target controlled infusion ( $\mathrm{TCl})$, paediatric anaesthesia

\section{Introduction}

Intraoperative neuromonitoring (IONM) has improved the safety of neurosurgical procedures but relies on avoiding volatile anaesthesia. Total intravenous anaesthesia (TIVA) for patients younger than one year is not possible using existing target-controlled infusion ( $\mathrm{TCl}$ ) devices. Applying the TCl pumps' pharmacokinetic (PK) models outside of their reference populations will lead to inaccurate dosing and is not recommended. PK models applicable for infants have been described and can be applied clinically using pharmacokinetic simulation software and advisory displays (e.g. Stelsim ${ }^{1}$ ). The technique comprises tracking a manually controlled infusion regimen in real time while displaying the estimated blood and effect-site concentrations, thereby assisting the clinician to maintain stable drug concentrations and stable drug effect. The method also enables titration of drug dosage to the patient requirements and facilitates timely emergence and extubation. We call the technique "target guided infusion (TGI)".

Propofol and remifentanil are the hypnotic and opioid of choice for TIVA in this age group for inter alia the rapidity of their onset and offset. We present a case requiring IONM and TIVA that involved an added challenge, namely unavailability of the opioid remifentanil.

\section{Case report}

A $3.1 \mathrm{~kg}$ term male infant, born via normal vertex delivery, was referred to our institution for repair of a cervical limited dorsal myeloschisis. At the time of corrective surgery, the baby was 3 months old, weighed $5.2 \mathrm{~kg}$ with a height of $54 \mathrm{~cm}$. Neurodevelopmental and growth parameters were appropriate. A soft, fluctuant mass was present over the upper thoracic and cervical vertebrae with intact overlying skin. Diagnosis of a

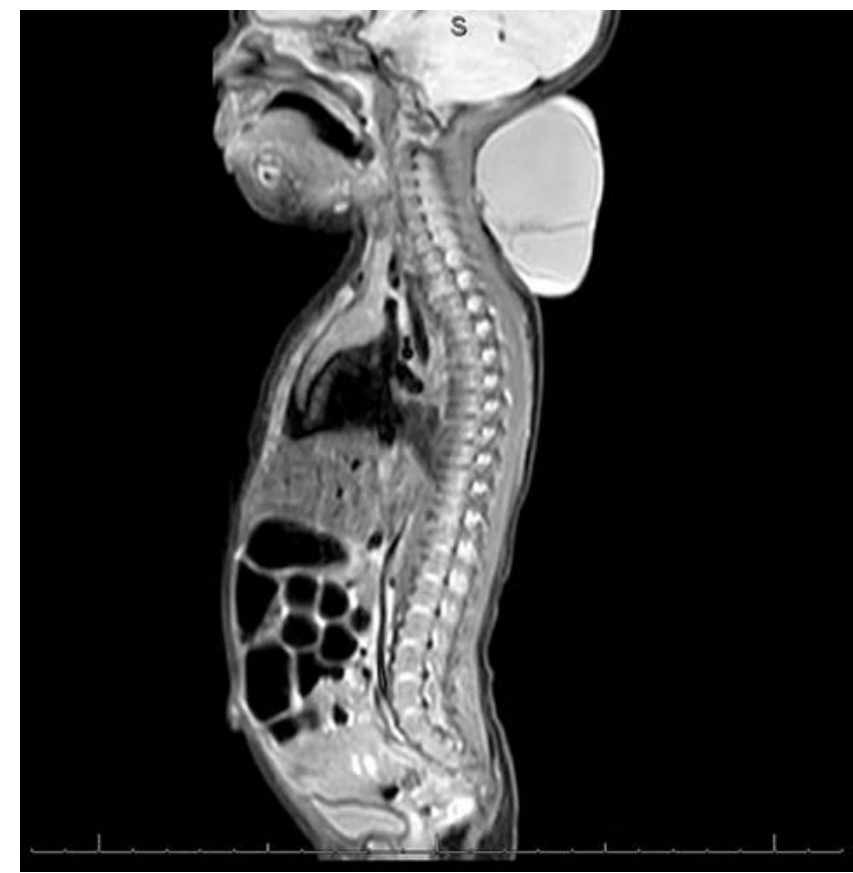

Figure 1. Magnetic resonance imaging of the cervical myeloschisis

A septated cystic lesion measuring $5.6 \times 3.8 \times 7.1 \mathrm{~cm}$ arising from the posterior central neck with tethered cord can be seen.

cervical limited dorsal myeloschisis was confirmed by magnetic resonance imaging (MRI) which revealed a septated cystic lesion measuring $5.6 \times 3.8 \times 7.1 \mathrm{~cm}$ arising from the posterior central neck (Figure 1). The cervical spinal cord at the level of C3/4 appeared to be tethered posteriorly with suspected cerebrospinal fluid (CSF) and cord connection into the mass.

Surgical resection with intraoperative neuromonitoring (IONM) was planned. Considering that remifentanil was unavailable in our hospital at that time due to a nationwide shortage, a decision 
Table I. Mammillary two and three-compartment model parameters for the three-month-old, $5.2 \mathrm{~kg}$ patient

\begin{tabular}{|c|c|c|c|}
\hline Model parameter & "Eleveld"2 (propofol) & "Goresky"3 (alfentanil) & Paedfusor $^{4} *$ (propofol) \\
\hline $\mathrm{V}_{1}(\mathrm{~L})$ & 1.25 & 1.25 & 2.34 \\
\hline$V_{2}(L)$ & 3.26 & 1.05 & 9.50 \\
\hline$V_{3}(L)$ & 20.1 & & 58.2 \\
\hline $\mathrm{CL}\left(\mathrm{L} \cdot \mathrm{min}^{-1}\right)$ & 0.225 & 0.045 & 0.219 \\
\hline $\mathrm{Q}_{2}\left(\right.$ L.min $\left.\min ^{-1}\right)$ & 0.648 & 0.019 & 0.267 \\
\hline $\mathrm{Q}_{3}\left(\right.$ L.min $\left.{ }^{-1}\right)$ & 0.071 & & 0.098 \\
\hline $\mathrm{k}_{10}\left(\mathrm{~min}^{-1}\right)$ & 0180 & 0.036 & 0.794 \\
\hline$k_{12}\left(\min ^{-1}\right)$ & 0.5184 & 0.015 & 0.114 \\
\hline $\mathrm{k}_{21}\left(\min ^{-1}\right)$ & 0.1988 & 0.018 & 0.055 \\
\hline$k_{13}\left(\min ^{-1}\right)$ & 0.0568 & & 0.0419 \\
\hline$k_{31}\left(\min ^{-1}\right)$ & 0.00353 & & 0.0033 \\
\hline$k_{e o}\left(\min ^{-1}\right)$ & 0.280 & $2.20 \dagger$ & $0.910 \dagger$ \\
\hline$t_{1 / 2} k_{e o}\left(\min ^{-1}\right)$ & 2.48 & $0.315+$ & $0.761+$ \\
\hline
\end{tabular}

$\mathrm{V}_{1}-\mathrm{V}_{3}$ apparent volumes of distribution; $\mathrm{CL}$ total body clearance, $\mathrm{Q}_{2}-\mathrm{Q}_{3}$ intercompartmental clearances; $\mathrm{k}_{10} \ldots \mathrm{k}_{31}$ micro rate constants; $\mathrm{k}_{\mathrm{eo}}$ effect-site equilibration rate constant, $t \frac{1}{2} \mathrm{k}_{\mathrm{eo}}$ effect-site equilibration half-time.

* Propofol "Paedfusor" model parameters for one-year old infants, illustrating inappropriateness for infants younger than 1 year

† estimated using algorithms from Minto et al. ${ }^{5}$ assuming a time to peak effect of 2.2 minutes.

Table II. The precalculated dose regimens for the first ten minutes to be administered to a three-month-old, $5.2 \mathrm{~kg}$ infant

\begin{tabular}{|c|c|c|c|c|c|c|}
\hline & Cumulative dose* & $\begin{array}{c}\text { Initial loading } \\
\text { dose† }\end{array}$ & $\begin{array}{c}\text { Remainder of } 10 \\
\text { min dose } \neq\end{array}$ & $\begin{array}{l}\text { Remainder } \\
\text { infusion rate }\end{array}$ & Syringe Conc. & $\begin{array}{l}\text { Pump rate } \\
\text { (mL/hour) }\end{array}$ \\
\hline $\begin{array}{l}\text { Propofol } \\
\left(C_{e} 3 \mu \mathrm{g} / \mathrm{mL}\right)\end{array}$ & $\begin{array}{c}25 \mathrm{mg} \\
(4.8 \mathrm{mg} / \mathrm{kg})\end{array}$ & $\begin{array}{c}16 \mathbf{~ m g} \\
(3 \mathrm{mg} / \mathrm{kg})\end{array}$ & $\begin{array}{c}9 \mathrm{mg} \\
(1.8 \mathrm{mg} / \mathrm{kg})\end{array}$ & $180 \mathrm{ug} / \mathrm{kg} / \mathrm{min}$ & $10 \mathrm{mg} / \mathrm{mL}$ & 5.6 \\
\hline $\begin{array}{l}\text { Alfentanil } \\
\left(C_{e} 90 \mathrm{ng} / \mathrm{mL}\right)\end{array}$ & $\begin{array}{c}166 \mu \mathrm{g} \\
(32 \mathrm{ug} / \mathrm{kg})\end{array}$ & $\begin{array}{c}104 \mu \mathrm{g} \\
(20 \mu \mathrm{g} / \mathrm{kg})\end{array}$ & $\begin{array}{c}62 \mu \mathrm{g} \\
(12 \mathrm{ug} / \mathrm{kg})\end{array}$ & $1.2 \mathrm{ug} / \mathrm{kg} / \mathrm{min}$ & $25 \mu \mathrm{g} / \mathrm{mL}$ & 15 \\
\hline
\end{tabular}

$\mathrm{C}_{\mathrm{e}}$ - targeted effect-site concentration

* Cumulative dose during the first 10 minutes as calculated by a Stelsim simulation for a three-month-old, $5.2 \mathrm{~kg}$ infant.

† Bolus dose given at initiation of TIVA

‡ Remaining dose = cumulative dose-bolus dose

was made to administer TIVA by TGI using propofol and alfentanil to facilitate IONM.

Because no appropriate pharmacokinetic (PK) models exist within currently available infusion pumps, we utilised Stelsim ${ }^{1}$ (version 2.04, Revision 1, August 2012) pharmacokinetic simulation software to guide both infusions. We pre-planned an initial bolus-and-infusion regimen calculated to rapidly achieve and maintain propofol and alfentanil effect-site concentrations of $3 \mu \mathrm{g} / \mathrm{mL}$ and $90 \mathrm{ng} / \mathrm{mL}$ respectively, employing the pharmacokinetic parameter sets of Eleveld ${ }^{2}$ for propofol and Goresky ${ }^{3}$ for alfentanil (Table I).

The dose regimens were planned as follows. Stelsim TCl simulations were conducted, targeting effect sites of $90 \mathrm{ng} / \mathrm{mL}$ for alfentanil and $3 \mu \mathrm{g} / \mathrm{mL}$ for propofol. From the simulations we obtained the initial loading doses to be administered, as well as the subsequent doses to be administered by infusion during the first ten minutes. The pre-calculated initial doses were thus administered to the patient manually, while the infusions were begun as indicated in Table II and the real-time Stelsim simulations were started. After the first ten minutes, the infusion rates were adjusted by observing the simulated effect-site concentrations and increasing or decreasing the infusion rates accordingly to maintain the $\mathrm{Ce}$ at the desired target. Anticipated recovery concentrations were set to propofol $1.3 \mathrm{ug} / \mathrm{mL}$ and alfentanil $60 \mathrm{ng} / \mathrm{mL}$.

The baby was positioned supine on an underbody forced air warming blanket with appropriate cushion support to avoid pressure on the myelomeningocele. After inhalational induction with sevoflurane, intravenous access was secured, sevoflurane was discontinued and propofol and alfentanil TGI were commenced using two Alaris ${ }^{\circ}$ TIVA (model 1000LB1411 Iss 2) (Cardinal Health, 1180 Rollse, Switzerland) infusion pumps in manual control mode.

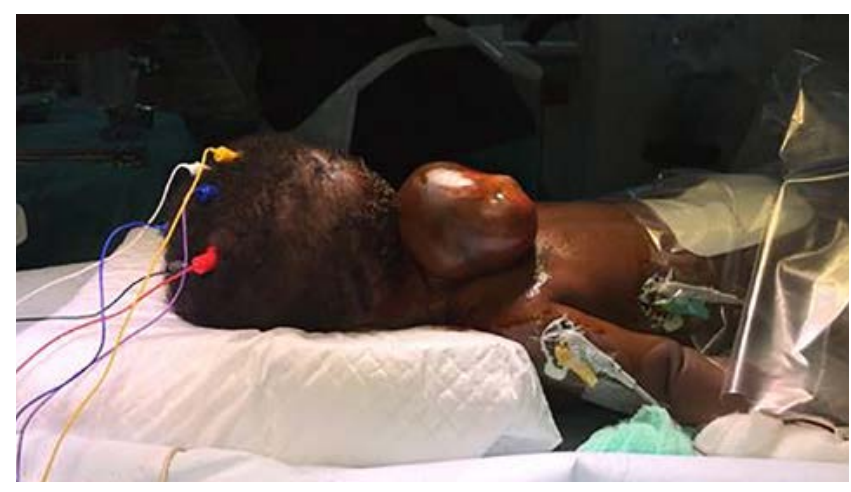

Figure 2. Patient ready for sterile cleaning and draping

Position prone with head resting on hollowed medium density foam block, ensuring no orbital pressure and adequate surgical access to the dorsal myeloschisis. IONM probes attached to scalp. 
A grade 1 laryngoscopy view was obtained with a Macintosh 1 blade and the cords were topicalised with $2 \%$ lignocaine to facilitate intubation while avoiding muscle relaxation. Arterial and central venous lines and a urinary catheter were inserted. The baby was turned to the prone position with its face supported on its forehead, cheeks and chin in the centre of a hollow foam support used for intubation and all pressure points were addressed. Prior to each anticipated increase in surgical stimulus during surgery, an alfentanil bolus of between 5-20 ug/kg was administered and recorded in Stelsim to maintain an accurate estimate of the predicted $\mathrm{Ce}$. Infusion rates were adjusted according to clinical response (heart rate, blood pressure, effect on evoked potentials) to maintain appropriate $\mathrm{Ce}^{\prime} s^{6,7}$ for surgical anaesthesia as predicted by Stelsim. Satisfactory somatosensory and motor-evoked potentials were achieved throughout the period of IONM.

Blood loss was approximately $100 \mathrm{~mL}$. The lowest recorded haemoglobin concentration was $7.5 \mathrm{~g} / \mathrm{dL}$ and $130 \mathrm{~mL}$ of crossmatched blood was transfused. At the conclusion of surgery, during closure of the subcutaneous layers, propofol and alfentanil Ce targets were lowered to $2.0 \mathrm{ug} / \mathrm{mL}$ and $80 \mathrm{ng} /$ $\mathrm{mL}$ respectively in order to decrease the time to recovery. This involved slowing/stopping the syringe pumps and restarting them at reduced infusion rates as the simulated effect-site drug concentrations approached the reduced targets. After application of wound dressings both infusions were stopped. Spontaneous breathing returned soon after repositioning in the supine position. Intravenous morphine $0.5 \mathrm{mg}$ and clonidine 5 $\mu \mathrm{g}$ were administered, and the baby's trachea was extubated while on the operating table four minutes prior to the predicted recovery time.

He appeared comfortable with normal gross motor function noted in all four limbs and was transferred to the paediatric intensive care unit while receiving nasal prong oxygen. Total procedure time was 3 hours 45 minutes. Figure 3 portrays the pump rates and the simulated drug concentrations. Total doses administered were propofol $148 \mathrm{mg}$, alfentanil $1033 \mu \mathrm{g}$.

\section{Discussion}

Cervical limited dorsal myeloschisis (CLDM) is rare. There may be tethering to the spinal cord and 50\% may involve neurological or orthopaedic anomalies, including hydrocephalus associated with Chiari II malformation ${ }^{8}$ and occult thoracolumbar spina bifida. The optimal timing for surgery is between six months and 1 year, unless neurological deterioration mandates earlier intervention. Surgery is performed in the prone position and involves laminectomy, intra-dural exploration and resection of septae and tethering bands. Intraoperative neuromonitoring (IONM) enhances surgical safety. IONM includes motor evoked potential (MEPs) monitoring, somatosensory evoked potential (SSEPs) monitoring and mapping of compound motor action potentials (CMAPs). Myelination is incomplete in children younger than three years, and it is important to avoid drugs that may impede signal conduction. Volatile anaesthetics and possibly dexmedetomidine ${ }^{9-12}$ may affect IONM, and therefore TIVA is the technique of choice. ${ }^{13-16}$ Muscle relaxants should be
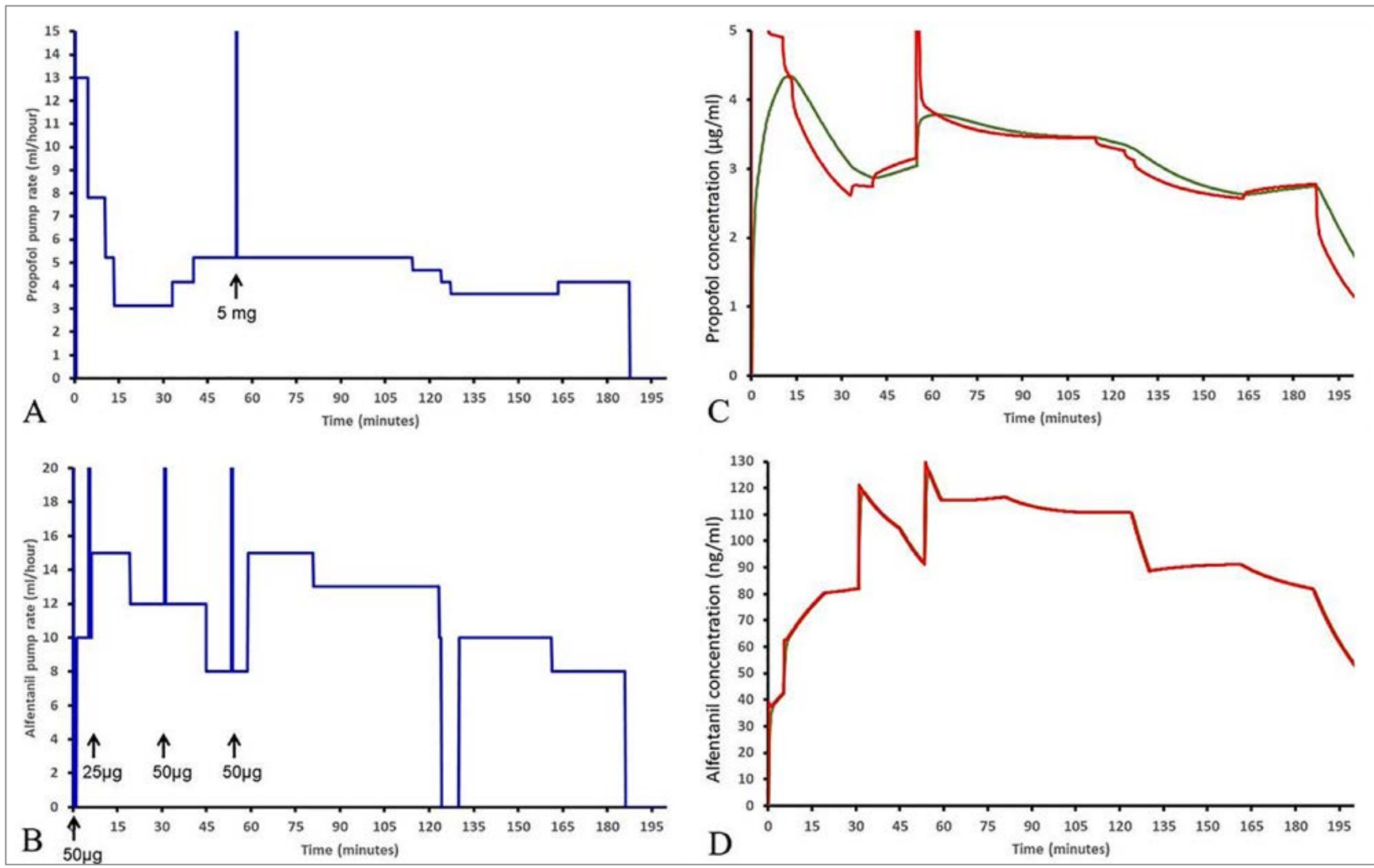

Figure 3. Syringe pump speeds and simulated blood and effect site concentrations over time

A and B: Syringe pump speeds over time. Arrows indicate supplementary bolus doses. A - Propofol; B - Alfentanil

C and D: Predicted blood (red) and effect site (green) concentrations. C - Propofol; D - Alfentanil 
avoided during MEP monitoring. Blood pressure and temperature should be maintained within normal limits to facilitate accurate interpretation of IONM readings. ${ }^{17}$

The requirement forTIVA in this patient presented two challenges; unavailability of remifentanil and TCI-pumps without ageappropriate PK models for sufentanil or alfentanil. There are no sufentanil PK studies available for infants aged less than one year undergoing non-cardiac surgery. The "Goresky" PK parameter-set for alfentanil ${ }^{3}$ is suitable for children aged between three months and 14 years. Stelsim simulations indicated that alfentanil would be suitable and that recovery would not be prolonged, even after prolonged infusions.

"Paedfusor"4 and "Kataria"18 paediatric propofol models used in commercially available $\mathrm{TCl}$ pumps have lower age limits of one and three years respectively. Using a PK model outside of its intended age group can result in significant dosage error ${ }^{19}$ (see Table I), as propofol pharmacokinetics vary significantly during the first 12 months. ${ }^{20}$ We used the recently published "Eleveld" broad application model ${ }^{2}$ which includes infant data. The model employs a maturation algorithm in addition to allometric scaling, thereby extending its lower age limit to infants and neonates below one year. The Eleveld model provides significant advantages over existing paediatric propofol models.

Similar to end-tidal volatile agent concentrations, advisory displays of expected plasma concentrations of infused intravenous drugs enable anaesthesiologists to fine-tune dosage according to patient requirements. ${ }^{21}$ Unlike end-tidal monitoring, patients' real plasma concentrations of infused drug will always differ somewhat from the simulation's display. Nevertheless, absolute prediction errors of $20 \%$ to $30 \%$ are clinically satisfactory. ${ }^{22-24} \mathrm{TCl}$ and TGI dose regimens are based on pharmacokinetic principles that enable clinicians to establish patients' drug concentrations within desired therapeutic windows and from there to titrate administration according to patient requirements. Useful guidelines for target concentrations have been published for individual drugs ${ }^{6}$ as well as for propofolopioid combinations. ${ }^{7}$

Several other TGI advisory display systems with larger drug libraries and up-to-date PK models are available, for example TIVA Trainer (Windows), iTIVA and TIVA Manager (Android). We used Stelsim because users can utilise any combination of PK parameters for any drug, since Stelsim allows users to manually program the pharmacokinetic parameters of drugs not contained in the software's original drug library. It is noteworthy that none of the newer models have been validated externally.

Recent developments include portrayal of drug-drug interactions based on response surface modelling. ${ }^{25}$ Two systems are commercially available, the Smart Pilot View (Drager, Lubeck, Germany) and the GE Navigator (GE Healthcare, Helsinki, Finland). Struys and co-workers provide a brief review of these advanced advisory display systems. ${ }^{26}$

\section{Conclusion}

Unavailability of essential drugs is a reality in developing countries such as South Africa. Difficulties in providing TIVA may be compounded by a non-availability of appropriate PK parameter-sets for patients at the extremes of age and size on $\mathrm{TCl}$ devices. This case illustrates how alternate drugs and advisory displays can be employed effectively. It also exemplifies the challenges of airway management and positioning of a small patient with a large CLDM.

\section{References}

1. Coetzee J, De Kock P. Stelsim. Stellenbosch: University of Stellenbosch; 2012.

2. Eleveld DJ, Colin P, Absalom AR, Struys MMRF. Pharmacokineticpharmacodynamic model for propofol for broad application in anaesthesia and sedation. Br J Anaesth. 2018 May; 120(5):942-59.

3. Goresky GV, Koren G, Sabourin MA, Sale JP, Strunin L. The pharmacokinetics of alfentanil in children. Anesthesiology. 1987;67(5):654-9.

4. Absalom A, Kenny G. 'Paedfusor' pharmacokinetic data set. Br J Anaesth. 2005 Jul;:95(1):110.

5. Minto CF, Schnider TW, Gregg KM, Henthorn TK, Shafer SL. Using the time of maximum effect site concentration to combine pharmacokinetics and pharmacodynamics. Anesthesiology. 2003 Aug;99(2):324-33.

6. Glass $P$, Shafer $S$, Reves J. Intravenous drug delivery systems. In: Miller R, editor. Miller's Anesthesia. 6th ed. Philadelphia: Elsevier; 2005. p. 439-80.

7. Vuyk J, Mertens MJ, Olofsen E, Burm AG, Bovill JG. Propofol anesthesia and rational opioid selection: determination of optimal EC50-EC95 propofolopioid concentrations that assure adequate anesthesia and a rapid return of consciousness. Anesthesiology. 1997 Dec 1;87(6):1549-62.

8. Huang S-L, Shi W, Zhang L-G. Characteristics and surgery of cervical myelomeningocele. Child's Nerv Syst. 2010 Jan 20;26(1):87-91.

9. Mahmoud M, Sadhasivam S, Salisbury S, Nick TG, Schnell B, Sestokas AK et al. Susceptibility of transcranial electric motor-evoked potentials to varying targeted blood levels of dexmedetomidine during spine surgery. Anesthesiology. 2010;112(6):1364-73.

10. Bala E, Sessler DI, Nair DR, McLain R, Dalton JE, Farag E. Motor and Somatosensory Evoked Potentials Are Well Maintained in Patients Given Dexmedetomidine during Spine Surgery. Anesthesiology. 2008 Sep;109(3):417-25.

11. Tobias JD, Goble TJ, Bates G, Anderson JT, Hoernschemeyer DG. Effects of dexmedetomidine on intraoperative motor and somatosensory evoked potential monitoring during spinal surgery in adolescents. Pediatr Anesth. 2008 Nov;18(11):1082-8.

12. Rozet I, Metzner J, Brown M, Treggiari MM, Slimp JC, Kinney G, et al. Dexmedetomidine does not affect evoked potentials during spine surgery. Anesth Analg. 2015 Aug;121(2):492-501.

13. Peterson DO, Drummond JC, Todd MM. Effects of halothane, enflurane isoflurane, and nitrous oxide on somatosensory evoked potentials in humans. Anesthesiology. 1986;65(1):35-40.

14. McPherson RW, Mahla M, Johnson R, Traystman RJ. Effects of enflurane, isoflurane, and nitrous oxide on somatosensory evoked potentials during fentanyl anesthesia. Anesthesiology. 1985;62(6):626-33.

15. Pathak KS, Ammadio M, Kalamchi S, Scoles P V, Shaffer JW, Mackay W. Effects of halothane, enflurane, and isoflurane on somatosensory evoked potentials during nitrous oxide anesthesia. Anesthesiology. 1987;66(6):753-7.

16. Vaugha DJ, Thornton C, Wright DR, Fernandes JR, Robbins $P$, Doré $C$, et al Effects of different concentrations of sevoflurane and desflurane on subcortical somatosensory evoked responses in anaesthetized, non-stimulated patients. $\mathrm{Br} J$ Anaesth. 2001 Jan;86(1):59-62.

17. Fulkerson DH, Satyan KB, Wilder LM, Riviello JJ, Stayer SA, Whitehead WE, et al. Intraoperative monitoring of motor evoked potentials in very young children. J Neurosurg Pediatr. 2011 Apr 1;7(4):331-7.

18. Kataria B, Ved S, Nicodemus $H$, Hoy $G$, Lea $D$, Dubois $M$, et al. The pharmacokinetics of propofol in children using three different data analysis approaches. Anesthesiology. 1994:80:104-22.

19. Wilson G. Target controlled infusion anaesthesia in children. South African J Anaesth Analg. 2010 Jan 12;16(1):124-6.

20. Anderson BJ. Pediatric models for adult target-controlled infusion pumps. Pediatr Anesth. 2010 Mar;20(3):223-32.

21. Syroid ND, Agutter J, Drews FA, Westenskow DR, Albert RW, Bermudez JC, et al. Development and evaluation of a graphical anesthesia drug display. Anesthesiology. 2002 Mar;96(3):565-75.

22. Varvel JR, Donoho DL, Shafer SL. Measuring the predictive performance of computer-controlled infusion pumps. J Pharmacokinet Biopharm. 1992 Feb 1;20(1):63-94.

23. Egan TD. Intravenous drug delivery systems: Toward an intravenous "vaporizer." $\rfloor$ Clin Anesth. 1996 May 1;8(3):S8-14.

24. Maitre PO, Ausems ME, Vozeh S, Stanski DR. Evaluating the accuracy of using population pharmacokinetic data to predict plasma concentrations of alfentanil. Anesthesiology. 1988 Jan;68(1):59-67.

25. Drews FA, Syroid N, Agutter J, Strayer DL, Westenskow DR. Drug delivery as control task: improving performance in a common anesthetic task. Hum Factors J Hum Factors Ergon Soc. 2006 Mar 6;48(1):85-94.

26. Struys MMRF, Sahinovic M, Lichtenbelt BJ, Vereecke HEM, Absalom AR Optimizing intravenous drug administration by applying pharmacokinetic/ pharmacodynamic concepts. Br J Anaesth. 2011 Jul;107(1):38-47. 